Montgomery, D. A. D., and Welbourn, R. B. (1957). Brit. J. Surg., 45, 137

Nabarro." J. D. N. Moxham, A., and Walker, G. (1958). J. clin. Endocr.. 18, 586.

Nelson, D. H., Meakin, S. W., and Thorn, G. W. (1960). Ann. intern. Med., 52, 560 .

Plotz, C. M., Knowlton, A. I., and Ragan, C. (1952). Amer. J. Med., 13, 597.

Siebennmann, R. E. (1955). Schweiz. Z. allg. Path., 18, 1189.

Sim, A. W., Hobkirk, R., Blair, D. W., Stewart, H. J., and Forrest, A. P. M. (1961). Lancet, 2, 73.

Skrimshire, J. F. P. (1955). Ibid., 1, 270

Sprague, R. G. (1953). Proc. roy. Soc. Med., 46, 1070

Weeks, R. E., Priestley, J. T., and Salassa, R. M. (1961) Modern Trends in Endocrinology, edited by $\mathrm{H}$. GardinerHill, p. 84. Butterworths, London

Steiner, J. W. Langer, B., Schatz, D. L., and Volpe, R. (1960). J. exp. Med., 112, 187.

$\overline{\underline{ }}$

\section{INDUCTION OF LABOUR BY INTRA- AMNIOTIC INJECTION OF HYPERTONIC GLUCOSE SOLUTION} BY

CARL WOOD, M.B., B.S., F.R.C.S., M.R.C.O.G. R. T. BOOTH, M.B.; B.S., M.R.C.O.G.

AND

JOHN H. M. PINKERTON, M.D., F.R.C.O.G.

From the Institute of Obstetrics and Gynaecology, Queen Charlotte's Hospital, London

Intrauterine death or foetal abnormality presents the obstetrician with a serious problem. Should he pursue a course of masterly inactivity, secure in the knowledge that at least he is doing no active physical harm to his potient ; or should he take steps to deliver her from her predicament as quickly as possible ?

On the whole immediate delivery, provided that it can be accomplished without undue risk to the mother, would seem preferable, and a safe reliable method of induction of labour in these cases would be a valuable addition to the armamentarium of the obstetrician. Intra-amniotic hypertonic solutions may provide such a method, and the preliminary trial of $50 \%$ glucose in water described below suggests that this is worthy of fuller investigation.

Brosset (1958) reported the successful induction of therapeutic abortion with $50 \%$ dextrose (usually followed by an intravenous drip of synthetic oxytocin) in 51 out of 54 patients between the 16th and 22nd weeks of pregnancy. He was " inclined to believe that a disturbance of the secretion of hormones of the ovum is brought about, the nature of which is still unknown " and this resulted in the expulsion of the products of conception.

Intrauterine hypertonic $20 \%$ saline was used successfully by Bengtsson and Csapo (1962) to induce therapeutic abortion in women between the 16th and 24th weeks of pregnancy. In a carefully planned series of experiments they produced evidence that the induction of labour by this procedure was due to diminished placental progesterone production. Although oxytocin alone (at infusion rates as high as 72 milliunits/minute for two consecutive days) did not terminate normal pregnancies between 16 and 24 weeks of gestation, a single intra-amniotic injection of $20 \%$ saline did so within 38 hours. They noted that after the intra-amniotic injection there was a marked fall in the blood and placental progesterone levels, while systemic progesterone given before the injection of the hypertonic saline delayed the onset of labour following this procedure from 31 to 68 hours. Also, progesterone has been shown to inhibit the propagation of the excitation wave in uterine muscle (Csapo, 1961).

In our series of late pregnancies (between the 28th and 40th weeks) glucose rather than saline was used because of the possible ill-effects to the mother of injecting approximately $40 \mathrm{~g}$. of sodium chloride into the uterus.

\section{Procedure}

There were 22 patients, including eight primigravidae ; 16 had intrauterine deaths of normally formed foetuses, and of the six congenital abnormalities two were live anencephalics (see Table).

Induction of Labour by Intra-amniotic Glucose in 22 Patients. Four Anencephalic Foetuses were Alive, All the Other Foetuses were dead at the time of induction

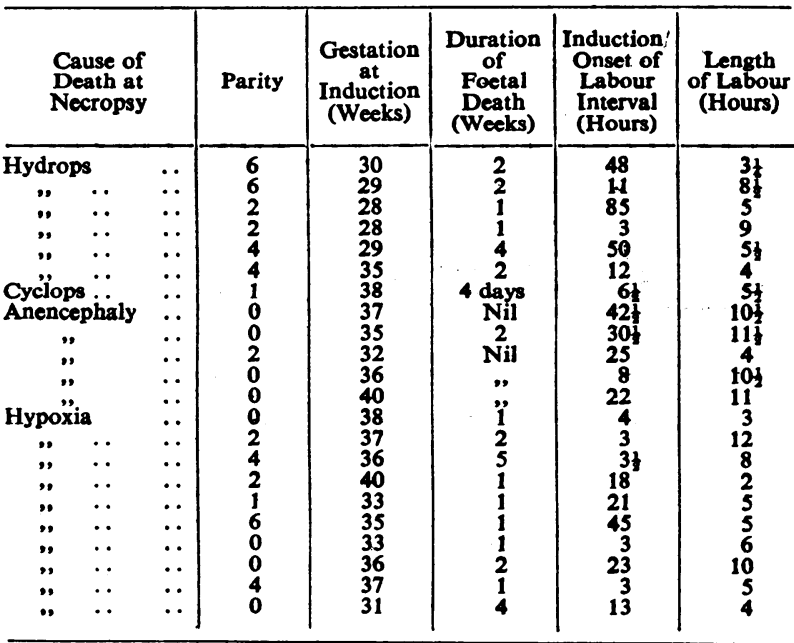

The patient emptied her bladder immediately before operation. After premedication local anaesthesia was induced with $0.5 \%$ procaine hydrochloride. A size 14 trocar and cannula was introduced into the uterus in the midline between the umbilicus and the symphysis pubis, taking care to avoid the upper edge of the bladder. The trocar was then removed and amniotic fluid flowing through the cannula showed that it was in the intra-amniotic space. In cases of foetal death the amniotic fluid is usually discoloured, often thick, and sometimes present in only very small amounts. A "polythene" catheter with an internal diameter of $1 \mathrm{~mm}$. and an external diameter of $2 \mathrm{~mm}$. was introduced into the amniotic cavity through the cannula, which was then removed. Amniotic fluid was first withdrawn, $200 \mathrm{ml}$. being removed where possible, and then $200 \mathrm{ml}$. of $50 \%$ glucose in water was injected through the polythene catheter, which was left in the uterus so that samples of amniotic fluid could be obtained for glucose-concentration estimations. Blood samples were also taken at regular intervals after the procedure was begun, for the same purpose.

In 12 patients the urinary excretion of oestrone, oestriol, oestradiol, and pregnanediol was measured. The intra-amniotic injection had to be repeated in two cases. In one the solution accidentally leaked out of the cannula and had to be replaced. In the other there was severe polyhydramnios and the injection of $250 \mathrm{ml}$. of $50 \%$ dextrose after the removal of some 3 litres of clear liquor under pressure failed to induce labour. The uterus was still very distended, and 48 hours later the procedure was repeated and another $250 \mathrm{ml}$. of $50 \%$ 
dextrose injected after the removal of $\mathbf{2 . 5}$ litres of liquor. It seems probable in this case that the injected glucose was so diluted by the gross polyhydramnios that it was ineffective.

\section{Results}

Labour was successfully induced in all patients, the duration of pregnancy varying from 28 to 40 weeks and the duration of foetal death up to five weeks. The delay between the time of induction and the onset of labour varied from 3 to 85 hours, the delay being 48 hours or longer on three occasions (see Table). It is possible that dilution of the $50 \%$ glucose diminished its efficiency in these three patients because in two of them the volume of amniotic fluid was excessive and in the remaining patient only $120 \mathrm{ml}$. of $50 \%$ glucose was injected because of technical difficulties. The interval between induction and the onset of labour could not be related to the parity of the patient or to the duration or cause of foetal death.

Labour was less than 13 hours in all cases and delivery of the placenta was spontaneous in all except one patient who required manual removal for retention of the placenta, a complication that had occurred in both her two previous pregnancies. Four of the anencephalics were alive at the time of induction: two died during labour: and two were live-born but died soon after birth (see Table).

Complications.-There were no serious complications. One patient developed a considerable exacerbation of her polyhydramnios, with abdominal pain, after the injection. This was thought to be due to rapid absorption of water into the amniotic sac across the placenta and membranes. There was no evidence of aecidental haemorrhage, and her symptoms subsided when the membranes ruptured spontaneously in labour. In another patient a small retroplacental haemorrhage was found after delivery, but there had never been any clinical evidence of abruptio placentae.

Urinary Oestrogens and Pregnanediol.-The excretion of urinary oestriol and pregnanediol in 12 patients in this series is shown in. Figs. 1 and $2 . \quad$ Urinary oestriol was low in all 12 , but urinary pregnanediol was low in six and within normal limits in six. There was no correlation between the length of time the foetuses had been dead and the pregnanediol levels, but the latter did seem to be related to the cause of death. Thus where death was due to hydrops foetalis the pregnanediol was normal in all four cases; but where death was associated with post-mortem evidence of foetal hypoxia the pregnanediol was low in five cases out of six ; and of two stillborn foetal abnormalities one was associated with normal and one with low urinary pregnanediol. It was also noted that the interval between induction and the onset of labour was usually short when the urinary pregnanediol was below average; in the four cases with a total excretion of less than $12 \mathrm{mg}$. $/ 24$ hours (normal average $20-60 \mathrm{mg}$. $/ 24$ hours) the interval was less than eight hours.

Glucose Levels in Maternal Blond and Amniotic Fluid

The wide variation in the blood (Fig. 3) and amniotic fluid (Fig. 4) concentrations following the injection may depend upon variations in the original volume of amniotic fluid, the rate of diffusion and mixing of glucose in this fluid, and the rate of absorption of glucose from the uterus. It was not possible to correlate the variations in the blood sugar with any clinical findings.
It was suggested by Bengtsson and Csapo (1962) that the effectiveness of glucose or saline in the induction of labour depended on its hypertonicity, and because of

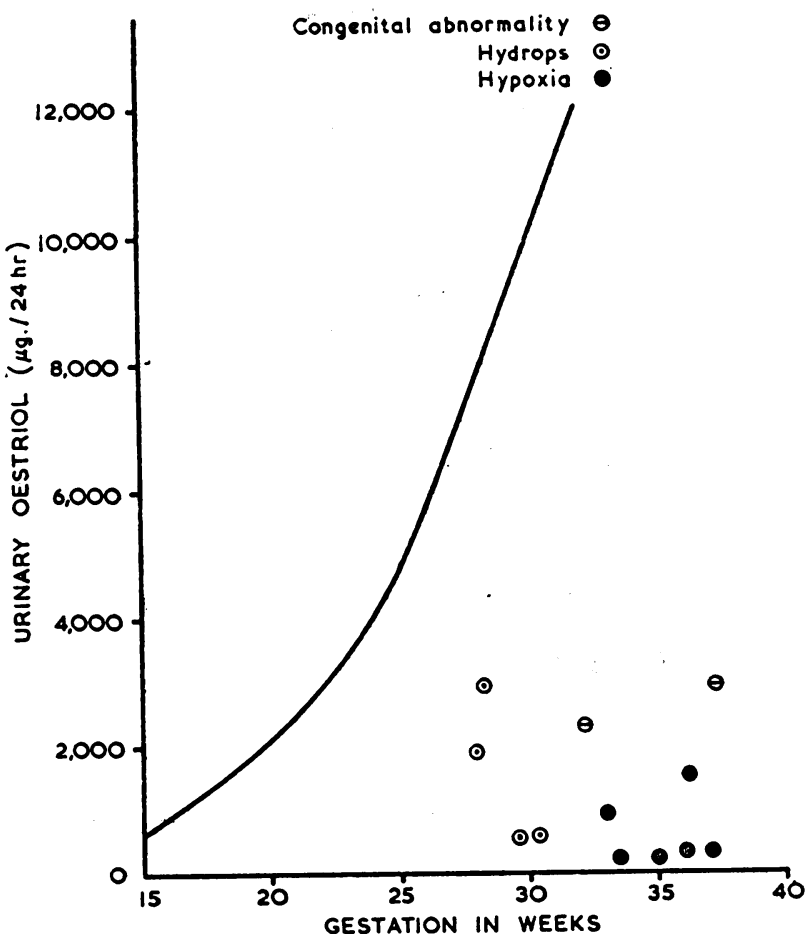

Fio. 1.-Urinary oestriol levels associated with intrauterine death of the foetus. The continuous line indicates the lower limit of the normal urinary oestriol range. The urinary oestriol levels were well below normal in all 12 cases.

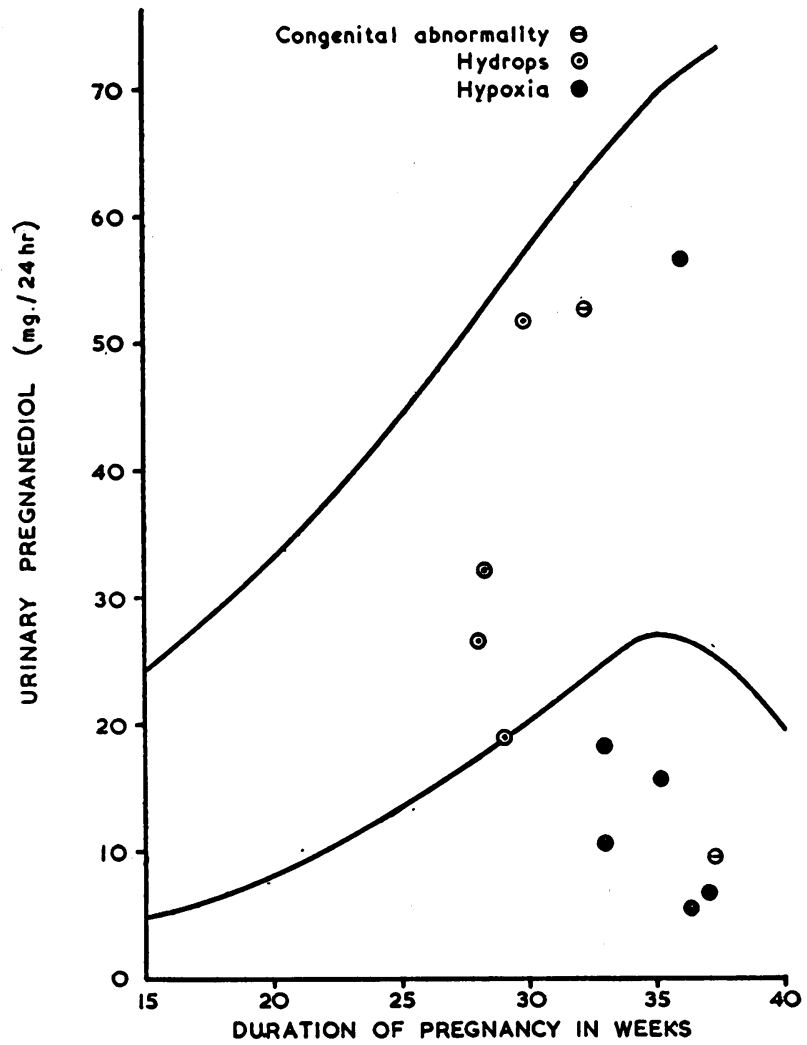

Frg. 2.-Urinary pregnanediol levels associated with intrauterine death of the foetus. The normal range of urinary pregnanediol lies between the continuous lines. Five out of six of the hypoxic deaths were associated with abnormally low levels, while five out of six of the deaths due to causes other than hypoxia were associated with normal levels. 
this the estimation of the glucose concentration of the amniotic fluid in the present series was of interest. In one patient the maximum glucose concentration in the amniotic fluid was only. $1.3 \mathrm{~g} . / 100 \mathrm{ml}$., and in three other cases the glucose concentration was always less than $5 \mathrm{~g} . / 100 \mathrm{ml}$. It might be thought that the low glucose concentrations in these cases were due to incomplete diffusion of the glucose throughout the amniotic fluid, but in three of them the glucose concentrations were still decreasing at the time of the last measurement (one was followed for 24 hours). The low glucose levels occurred in patients with an excess of amniotic fluid, when considerable dilution of the hypertonic glucose would occur. As the onset of labour was 24 to 48 hours after the induction in these cases it is unlikely that this was due either to a coincidental spontaneous onset of labour in the four patients or to any stimulation of uterine activity by the amniotomy itself. Therefore it seems

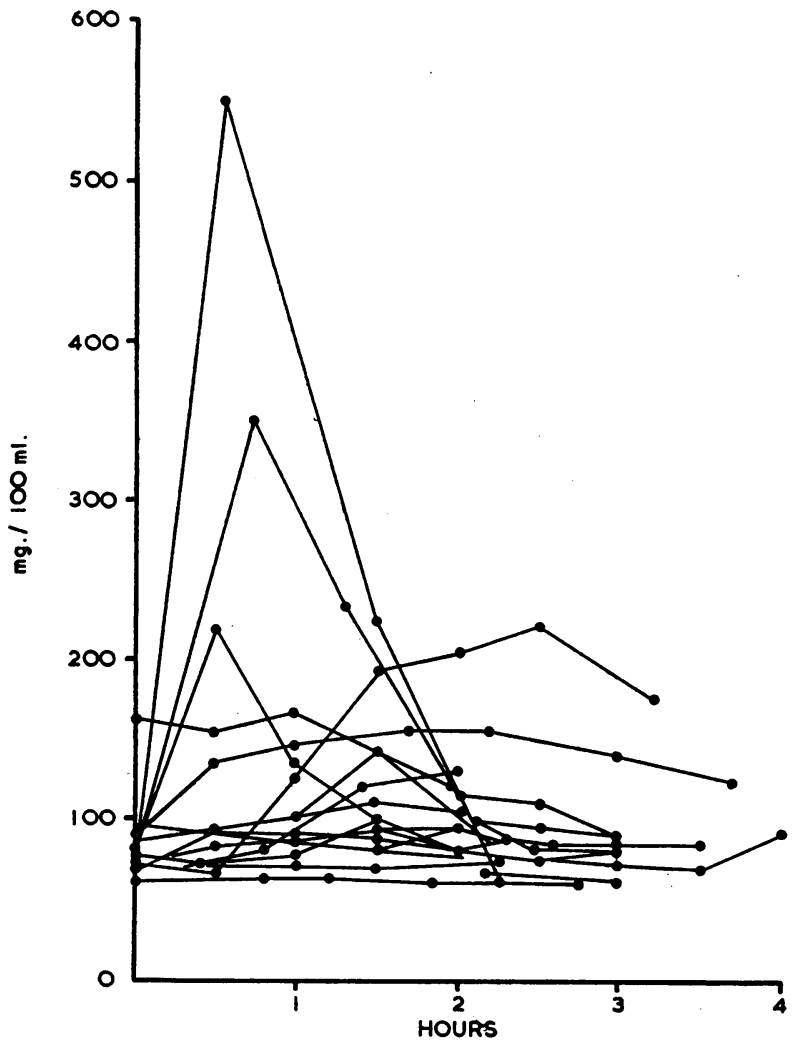

Fig. 3.-Maternal blood glucose levels following the intraamniotic injection of $200 \mathrm{ml}$. of $50 \%$ glucose.

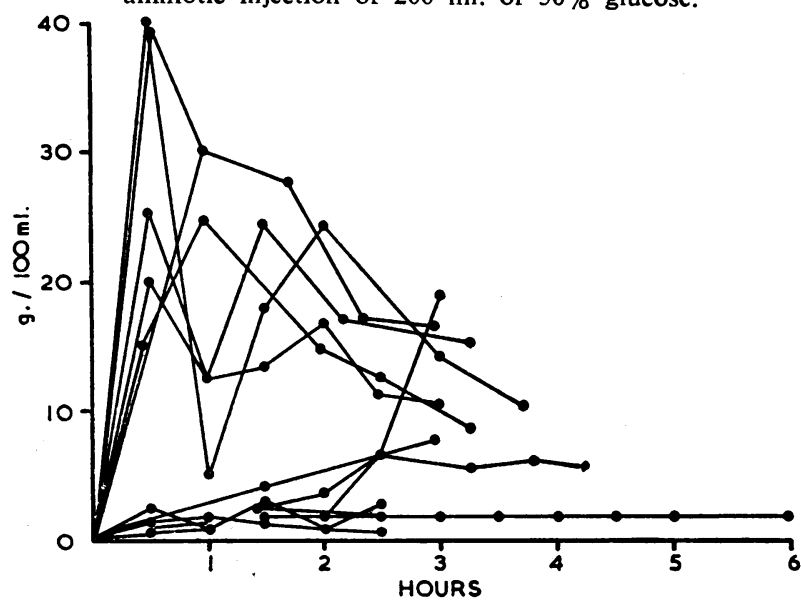

Fig. 4.-Amniotic glucose levels following the intra-amniotic injection of $200 \mathrm{ml}$ of $50 \%$ glucose. probable that labour was induced by producing only a slight increase in the total osmolarity of the amniotic fluid.

After the injection of hypertonic glucose one patient developed polyhydramnios; her girth increased from 40 to $43 \frac{1}{2}$ in. (101.5 to $110.5 \mathrm{~cm}$.) in 24 hours, and more than 6 litres of amniotic fluid escaped when the membranes ruptured spontaneously in labour. The maximum concentration of glucose in this patient's liquor was $1.95 \mathrm{~g} . / 100 \mathrm{ml}$. and it fell gradually over the next 24 hours to $1.2 \mathrm{~g} .1100 \mathrm{ml}$. The maternal blood sugar remained fairly constant around $90 \mathrm{mg} . / 100 \mathrm{ml}$.

\section{Discussion}

Successful induction of labour was achieved in 22 patients in late pregnancy by the intra-amniotic injection of $50 \%$ glucose in water. The procedure was technically simple and produced no serious complications. The induction of therapeutic abortion by hypertonic saline in 98 cases (Fuchs, 1961 ; Bengtsson and Csapo, 1962) and hypertonic glucose in 51 cases (Brosset, 1958) confirms the effectiveness and safety of this technique as a method of induction of labour.

While Bengtsson and Csapo have accumulated considerable evidence that the onset of labour following the intra-amniotic injection of hypertonic saline is due to a fall in placental progesterone production, some doubt this theory because they believe that changes in uterine volume during the induction might result in the onset of labour. Prior to the intra-amniotic injection of the solution amniotic fluid is usually removed from the uterus, and it may be thought that this may stimulate uterine activity. This is unlikely, because in several patients the method was effective when no amniotic fluid could be removed from the uterus. Also, low amniotomy in the last trimester is not always effective in inducing labour, and the interval before the onset of labour when this does occur is sometimes prolonged.

Further evidence that volume reduction is not a vital factor in the induction of labour was obtained in late pregnancy (Csapo et al., 1962), when it was found that abdominal amniotomy and the withdrawal of amniotic fluid did not usually increase uterine activity. After the introduction of $50 \%$ glucose in water the uterine volume may increase owing to the absorption of water into the amniotic space, and it may be argued that this would increase uterine activity, for there is some evidence in late pregnancy that increasing the uterine volume enhances the activity of the myometrium (Csapo et al.; 1962). But in mid-pregnancy this has not been demonstrated, and, indeed, Brosset (1958) has shown that an increase in uterine volume with solutions other than hypertonic glucose did not induce labour, and it seems likely, therefore, that the hypertonic glucose cannot be acting merely by increasing uterine volume.

Another objection to Csapo's theory has been that the hypertonic solution may act as a direct stimulant or irritant to the uterine muscle, but the intra-amniotic pressure does not in fact increase for several hours after the injection of hypertonic saline and so its action is unlikely to be due to a direct irritation of the myometrium. Also, in vitro experiments with smooth muscle have produced evidence that hypertonic solutions of this degree will not stimulate uterine activity.

If the onset of labour following the intra-amniotic injection of $20 \%$ sodium chloride is due to a reduction of placental progesterone production, then the bitth of 
two live anencephalics and the absence of histological degenerative changes in the placenta in the present series suggests the possibility of interfering with placental hormone production without necessarily affecting placental transport function. This may well be the case, as Cassmer (1959) has produced experimental evidence that dissociation of even oestrogen and progesterone production by the placenta can occur. The successful induction of labour in four patients when the glucose concentration of the amniotic fluid was always less than $5 \mathrm{~g}$. $/ 100 \mathrm{ml}$. suggests that replacement of the amniotic fluid with solutions of lower tonicity than $50 \%$ glucose may also be effective in the termination of pregnancy.

Bengtsson and Csapo's theory that the onset of labour is due to a fall in progesterone production by the placenta is an attractive one and is supported by their endocrinological and histological findings. We have, unfortunately, no comparable endocrinological studies of the plasma progesterone before and after the injections (see Addendum), but gross and histological examination of the membranes and placenta disclosed no evidence of change in any of our cases. While this is in contrast to their findings of haemorrhages and infarcts of the placenta, it is in agreement with Brosset's findings in mid-pregnancy.

The association of deaths due to hypoxia with low urinary pregnanediol and deaths due to hydrops or foetal abnormality with normal levels is interesting. Von Wagenan and Jenkins (1939) first showed in the rhesus monkey that removal of the foetus early in pregnancy did not disturb the placenta, which remained in situ and active till near term. Cassmer (1939) showed that interruption of the circulation in the human umbilical cord during mid-pregnancy was followed by a rapid fall in urinary oestrogen but only a slight decrease in urinary pregnanediol. His experiments indicated that the foetal circulation is essential for the maintenance of the urinary oestrogen levels in pregnancy but not for the production of progesterone. If we assume that the hypoxic deaths in our series are secondary to placental failure, and if the deaths due to hydrops are regarded as primarily foetal, then our findings of low pregnanediol and low oestrogen levels in the former and low oestrogen levels only in the latter are in agreement with Cassmer's results.

\section{Summary}

Labour was successfully induced during the last trimester by injecting $50 \%$ glucose solution into the amniotic cavity through the abdominal wall. The method was used in 22 consecutive patients with foetal abnormalities or intrauterine death.

The method appears to be simple, safe, and sure, and would seem to be worthy of more extensive trial. All patients were delivered spotaneously within 96 hours of induction, and labour was less than 13 hours in all cases.

In several patients serial measurement of the amniotic glucose concentrations revealed values that were always less than $5 \mathrm{~g} . / 100 \mathrm{ml}$., which suggests that the replacement of the amniotic fluid with solutions of lower tonicity than $50 \%$ glucose might also be effective in the induction of labour.

The interval between induction and onset of labour was usually short when the urinary pregnanediol excretion was low. When foetal death was due to hydrops foetalis the urinary pregnanediol excretion was normal, but when death was associated with postmortem evidence of foetal hypoxia it was usually low.

Evidence is given that the onset of labour following this procedure is not due to a change in uterine volume nor to a direct effect of the glucose upon the myometrium; available data suggest that the intraamniotic injection of $50 \%$ glucose induces labour by diminishing placental progesterone production.

We are indebted to Dr. Arpad Csapo for his useful suggestions during the preparation of this paper; to Dr. I. Sommerville and Dr. M. Stern for the hormone assays; to Dr. M. Sandler for the glucose determinations; to Dr. A. E. Claireaux for the histological studies; to Miss J. Farebrother, senior labour ward sister, Dr. R. W. Beard, and Dr. J. Gibson for their help ; and to all our consultant colleagues who referred patients to us.

ADDENDUM.-Since the completion of this study blood-progesterone estimations have been performed on two patients, one with a live anencephalic and one with a dead foetus. The blood-progesterone levels before and 3 to 17 hours after the intra-amniotic injection of $50 \%$ glucose showed no significant difference.

\section{REFERENCES}

Bengtsson, L. P., and Csapo, A. (1962). In preparation

Brosset, A. (1958). Acta obstet. gynec. scand., 37, 519.

Cassmer, O. (1959). Acta endocr., Suppl. 45.

Csapo, A. (1961). In Progesterone and the Defence Mechanism of Pregnancy, edited by G. E. W. Wolstenholme and Margaret P. Cameron. Churchill, London.

Jaffin, H., Kerenyi, T., Lipman, J., and Wood, C. (1962). In preparation

Fuchs, F. (1961). In Progesterone and the Defence Mechanism of Pregnancy, edited by G. E. W. Wolstenholme and Margaret P. Cameron. Churchill, London

Von Wagenan, G., and Jenkins, R. H. (1939). J. Urol., 42, 1010.

\section{UNRECOGNIZED CARCINOMA OF CAECUM PRESENTING AS ACUTE APPENDICITIS OR APPENDIX ABSCESS}

BY

\author{
M. A. HOSSAIN, M.B., F.R.C.S., F.R.C.S.Ed. \\ Formerly Surgical Registrar, the Royal London \\ Homoeopathic Hospital
}

The classical manifestations of carcinoma of the caecum, such as anaemia, loss of weight, and a mass in the R.I.F., in patients of cancer age hardly pose a problem in diagnosis ; but when caecal cancer presents for the first time in an emergency as acute appendicitis or appendix abscess diagnostic difficulties become great, and not infrequently the basic lesion goes unrecognized long enough to spoil the prospects of surgical cure. In an analysis of a series of cases of cancer of the right colon Mayo (1947) reported that 15\% and Ransom (1952) that $11 \%$ of the patients had had their appendix removed without recognition of the underlying carcinoma. Similar mistakes have been reported by Costello and Saxton (1951), and by Hellsten and Ramström (1951). Undoubtedly appendicitis in association with carcinoma of the caecum occurs more often than is realized and will become more frequent with the increase of ageing population.

The number of cases of the dual condition so far reported in the literature is not large. Probably delay in diagnosis and poor results discourage publication. Sometimes emergency appendicectomy and treatment of the carcinoma are not carried out in the same hospital. 